\section{Hemolymph Ecdysteroid Titers and Pupal Cuticle Synthesis in Mamestra brassicae ${ }^{1}$}

\author{
Kiyoshi Hiruma ${ }^{2}$ and Noriaki Agur ${ }^{3}$ \\ Department of Medical Entomology, The National \\ Institute of Health, Kamiosaki, Shinagawa-ku, \\ Tokyo 141, Japan
}

\section{(Received October 5, 1984)}

Ecdysteroid titers have been measured by radioimmunoassay (RIA) in many insects. Since it is easy to ligate lepidopteran larvae, the ecdysteroid concentration of the critical periods for pupal ecdysis were investigated by ligation experiments in Pieris brassicae (LAFont et al., 1977), Calpodes ethlius, Manduca sexta, Galleria mellonella (DeAn et al., 1980), Mamestra brassicae (Agur and Hiruma, 1982) and Spodoptera litura (Tojo et al., 1984). In most ligatured lepidopteran larvae, the concentration at the end of the critical period is less than half-fold of the maximal levels seen in intact larvae, suggesting that much less ecdysteroid is necessary for pupal cuticle synthesis than is secreted into the hemolymph. In this paper, we describe the minimal ecdysteroid concentration necessary for pupal cuticle synthesis in vivo.

Larvae of the cabbage armyworm, Mamestra brassicae, were reared on an artificial diet (AGUI et al., 1975) at $25^{\circ} \mathrm{C}$ under a long-day photoperiod (16L-8D). They were reared under aseptic conditions until the 4th instar. The last (6th) instar larvae purged their guts and entered the wandering stage 5 days after ecdysis, then formed non-diapausing pupae. Ecdysteroid levels were determined by ecdysone-RIA described by Borst and O'CONNOR (1972) and Grlbert et al. (1977). RIA antiserum was prepared against a hemisuccinate derivative of ecdysone at the C-22 hydroxy position only; the labeled ligand for RIA was $\left[23,24-{ }^{3} \mathrm{H}\right]$ ecdysone (57 Ci/mmole). The antibody had similar specificity for ecdysone and 20-hydroxyecdysone (Grlbert et al., 1977). Hemolymph samples (10 $\mu l)$ were extracted with 20-30 times volume of absolute methyl alcohol, and then centrifuged at $2,500 \mathrm{~g}$ for $20 \mathrm{~min}$. Aliquots of the supernatant were assayed for ecdysteroid.

When we implanted a brain taken from day 7 last instar larva into neck-ligatured day 5 last instar larvae, $70-80 \%$ of the ligatured larvae pupated after 10-12 days; in contrast, ligatured larvae lacking implants did not pupate even after 30 days as shown in Hiruma and Agur (1977). To investigate the relationship between ecdysteroid concentration and pupal cuticle synthesis, the hemolymph was collected various days after the operation from the mesothoracic leg of the ligatured larva for ecdysteroid content, then ligation was performed again between thorax and abdomen immediately after the bleeding so that the abdomen was available for further morphological observation. We compared the amount of ecdysteroid with further morphological changes of the isolated abdomen. As shown in Fig. 1, although the isolated abdomens containing more than about $400 \mathrm{ng} / \mathrm{ml}$ ecdysteroids pupated later, the abdomens less than 150-200 ng/ml ecdysteroids did not show any morphological changes. Intermediate concentrations of $200-400 \mathrm{ng} / \mathrm{ml}$ induced incomplete or mosaic synthesis of cuticle as shown in Manduca (Truman et al., 1974). These results show that about one-third of the maximal titer (400 $\mathrm{ng} / \mathrm{ml}$ ) ecdysteroid is enough to make pupal cuticle; the maximal titer in vivo being $1,250 \mathrm{ng} / \mathrm{ml}$ ecdysteroid. This coincides with the concentration $(350 \mathrm{ng} / \mathrm{ml}$ ) associated with $50 \%$ pupation of the thoraxabdomen ligatured larvae on day 7 , which is the end of the critical period of ecdysteroid secretion for pupation (AGUI and Hiruma, 1982). In Spodoptera, about $200 \mathrm{ng} / \mathrm{m} l$ ecdysteroids, which is about one-third of the maximal level, is sufficient for the synthesis of pupal cuticle, and $100 \mathrm{ng} / \mathrm{ml}$ is enough to cause sequestration of the storage protein into the fat body (Tojo et al., 1984). Higher concentration of ecdysteroids are probably required for other metamorphic changes, such as degradation of the silk glands in Bombyx mori (CHINzer, 1975), epidermal RNA synthesis and protein sequestration by the fat body (DEAN et al., 1980) etc.

Figure 1 also shows that the implanted brain begins to secrete enough prothoracicotropic hormone (PT'TH) to activate the prothoracic glands

\footnotetext{
Appl. Ent. Zool. 20 (1): 97-98 (1985)

Present address: Department of Zoology, University of Washington, Seattle, Washington 98195, U.S.A.

3 To whom reprint should be addressed.
} 
by 5 days after the implantation. Since prothoracic glands cultured in vitro with brain homogenate synthesize ecdysone at maximal level for 6-12 hr

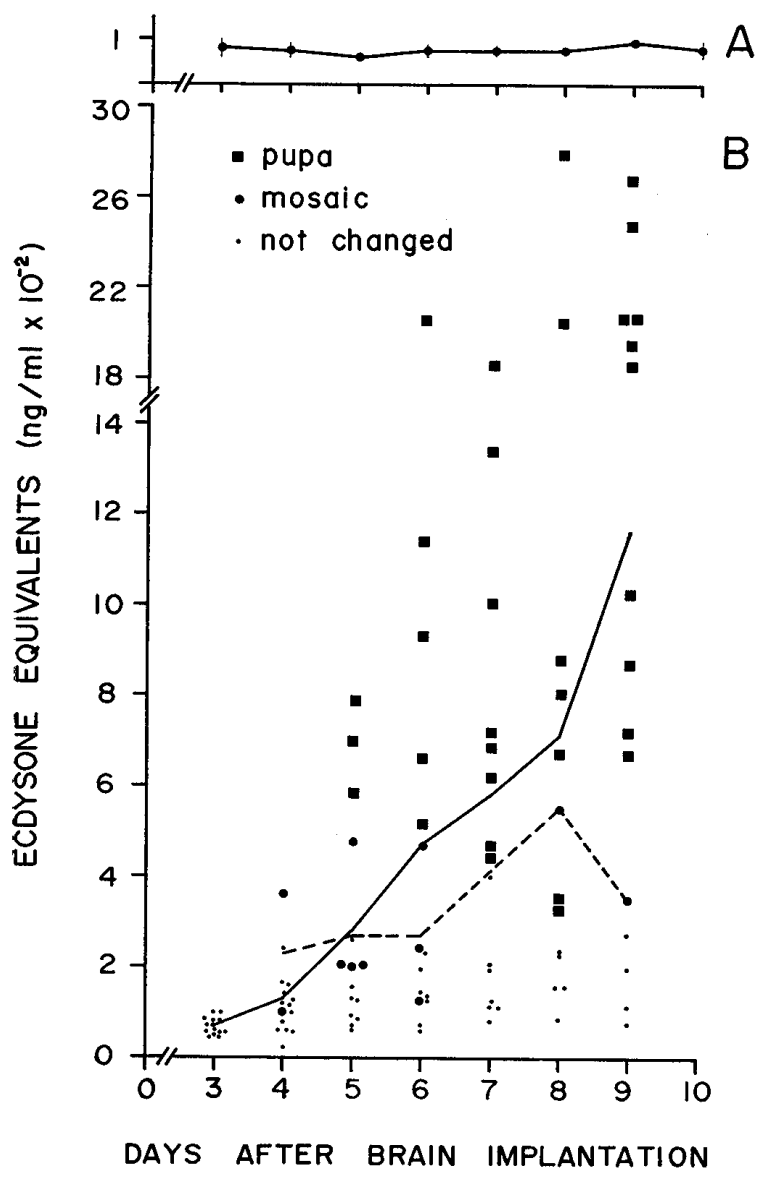

Fig. 1. A: ecdysteroid concentration in the hemolymph of neck-ligatured larvae. Each point represents the mean of 4 determinations $\pm S D$. Animals did not show any changes in appearance for at least 30 days after ligation. B: ecdysteroid concentration in the hemolymph and further morphological changes of ligatured larvae receiving brain implants. Each symbol shows ecdysteroid titer of the larvae pupated ( $\mathbf{a})$, undergone mosaic moulting (•) and given no change $(\cdot)$ at the day showing abscissa. Brains were taken from larvae 2 days after gut purge and implanted into neckligatured larvae just emptied their gut content. Implantation (a brain per larva) was done shortly after the ligation. Solid line: mean ecdysteroid concentration of the all animals at each day showing abscissa. Dotted line: mean ecdysteroid concentration of the larvae which underwent mosaic moulting and did not synthesize a complete cuticle. in Manduca (Bollenbacher et al., 1979), Bombyx and Mamestra (Agur et al., 1983), this lag period might be due to impaired function of the isolated brain and/or with adjustment of the brain to the new milieu. In addition, the prothoracic glands of the some animals synthesized huge amounts of ecdysteroids under stimulation by isolated brains; in some cases the concentrations were more than twice $(2,000-2,800 \mathrm{ng} / \mathrm{ml})$ that of the normal ecdysteroid titer. Thus, it seems likely that innervation and neural regulation is necessary to control the timing and the amount of secretion of PTTH by the brains.

We wish to thank Dr. Nancy E. Beckage, Issaquah Health Research Institute, for her critical reading of the manuscript. Thanks are also due to Dr. L. I. Gilbert and Dr. W. E. Bollenbacher, University of North Carolina, for supplying ecdysone antibody.

\section{REFERENCES}

Agur, N. and K. Hiruma (1982) Appl. Ent. Zool. 17: $144-146$.

Agui, N., W. E. Bollenbacher and L. I. Gilbert (1983) Experientia 39: 984-988.

Agui, N., N. Ogura and M. Okawara (1975) Jap. J. appl. Ent. Zool. 19: 91-96 (in Japanese with an English summary).

Bollenbacher, W. E., N. Agui, N. A. Granger and L. I. Grlbert (1979) Proc. Nat. Acad. Sci. U.S.A. 76: 5148-5152.

Borst, D. W. and J. D. O'Connor (1972) Science 178: $418-419$.

Chinzei, Y. (1975) Appl. Ent. Zool. 10: 136-138.

Dean, R. L., W. E. Bollenbacher, M. Locke, S. L. Smith and L. I. Gilbert (1980) J. Insect Physiol. 26: 267-280.

Gilbert, L. I., W. Goodman and W. E. BollenBACHER (1977) In International Review of Biochemistry, Biochemistry of Lipids II. (T. H. Goodwin, ed.), University Park Press, Baltimore, 14: $1-50$.

Hiruma, K. and N. Agui (1977) Appl. Ent. Zool. 12: $42-49$.

Lafont, R., B. Mauchamp, C. Blais and J.-L. Pennetier (1977) J. Insect Physiol. 23: 277-283.

Tojo, S., M. Morita, N. Agur and K. Hiruma (1985) J. Insect Physiol. (in press).

Truman, J. W., L. M. Riddiford and L. Safranek (1974) Dev. Biol. 39: 247-262. 